\title{
Corpo: objeto de estudo
}

\author{
Corpos de passagem: ensaios \\ sobre a subjetividade \\ contemporânea.
}

SANT'ANNA, Denise Bernuzzi de.

São Paulo: Estação Liberdade, 2001. $127 \mathrm{p}$.

Na década de 1990, Denise B. de Sant'Anna publicou dois livros problematizando o corpo, além de diversos artigos. A obra Corpos de passagem, ainda um desdobramento dessa reflexão, reúne dez ensaios que foram escritos na mesma década e publicados ou apresentados, integralmente ou parcialmente, em diferentes meios (jornal, revista, mesa-redonda e, certamente, rascunhos do debate acadêmico). Historiadora da PUC-SP, doutorada pela Universidade de Paris VII, Denise B. de Sant'Anna vem ampliar os questionamentos que a sociedade e, em especial, a academia têm feito sobre o corpo, que passa a ser objeto de estudo a partir da década de 1970.

A exploração comercial do corpo, questão levantada por Denise Sant'Anna, trouxe, paradoxalmente, a 'desertificação da vida'. Quanto mais se explora o corpo, mais ele se torna infinito, rompem-se as fronteiras territorias. O corpo não é mais uma unidade, mas um elo entre os corpos. As pesquisas genéticas estão criando transgênicos e seres pós-gênero, no entanto as desigualdades sociais permanecem. Essas são discussões especialmente presentes no sétimo e no oitavo ensaio.

O corpo como equivalente de riqueza e explorado pelo mercado é a tônica das reflexões da autora. A estética aerodinâmica suavizando as linhas, a tecnologia virtualizando a pessoa viva, cria um abismo "entre os nossos", diz ela. O deslocamento é valorizado: viagens de férias, spas ou resorts, esportes radicais... Prometeu reaparece como aquele que vence suas próprias limitações ou conquista seu próprio empreendimento. Ou seja, o indivíduo domina a si mesmo ou os espaços, transformando a natureza, recriando cidades onde passeia sem medo - é a 'indústria da alegria' -, temas tratados no terceiro e no quarto ensaio.

A velocidade também passa a ser condição de sucesso, poder e riqueza, mostra a autora no primeiro ensaio. Aquele que se quer desvencilhar do peso de tudo "teme carregar muito corpo, muita memória, muita identidade. E se vê ameaçado constantemente pela vertigem da compulsão e pela depressão aniquiladora" (p.25), conclui Denise. E faz pensar que os apelos do mercado colocam a vida na moda. Então, envelhecer ou morrer também se comercializa, pois a imortalidade é aqui, nesta vida.

Enquanto a exposição do corpo ganha publicidade, o interior do corpo provoca náuseas. Até bem pouco tempo, doentes eram tratados em casa, bem como galinhas e porcos que além de serem tratados eram mortos em casa. Os penicos ficavam em baixo da cama. A menstruação passava pelas mãos que lavavam as toalhinhas. Sangue, fezes e urina faziam parte da rotina. "Na medida em que o corpo ganha direito de exposição, ele conquista o dever de ser civilizado e fotogênico" (p. 69), coloca a autora, no quinto ensaio. No segundo, mostra como o hospital deixa o corpo 'paciente' aos cuidados e especialidades de estranhos. Estar doente não é mais 'natural'. A dor, que no século XIX era sinônimo de coragem e persistência, deve ser banida. A vida do doente é como se não fosse vida, passa a ser um momento intervalar.

O nono ensaio polemiza a idéia que deu origem ao título do livro: o corpo-passagem. A idéia de possessão como um lugar de passagem. Aquela máxima feminista, da década de 1960, "nosso corpo nos pertence",' que pretendia ser um contraponto da dominação do homem sobre a mulher, não só se esvazia como nos remete a pensarmos que nossos corpos não pertencem a ninguém, nem a nós mesmos. Na metáfora utilizada pela própria autora, o corpo é parodoxal 
à medida que não é algo pronto mas também não é um rascunho. Somos e temos um corpo sempre de passagem. Não no sentido cristão de passagem para o céu, embora para alguns também possa ser, mas no sentido de que um mesmo corpo possa assumir formas (plasticidades e comportamentos) em diferentes momentos ou em um mesmo momento. O corpo pode estar em um determinado local e em outro ao mesmo tempo, pode estar parado e em movimento... As polaridades já foram superadas pelas reflexões contemporâneas da subjetividade. E Denise Sant'Anna coloca essas questões nesse livro, embora avise dos riscos de cair na areia movediça da valorização do corpo que carrega a 'universalidade' do indivíduo, onde habita sua pátria, seus sucessos e fracassos. Os conceitos universais de Deus, Nação podem, e têm sido transferidos para a noção de indivíduo. O mercado e a publicidade mostram que a felicidade pode ser comprada, que as coisas e os bichos podem ser humanizados (nos falam, nos incitam, os animais conversam, fazem companhia...). Valores como liberdade, democracia e cidadania são definidos como conseqüências do consumo. As sutilezas provocam outras palavras, histórias, personagens e corpos, conclui a autora.

Denise não quer ser definida como uma historiadora do corpo, embora os corpos e suas relações tenham historicidade. Ela não se preocupou com as relações de gênero, talvez porque não quisesse problematizar a sexualidade, que vem sendo objeto de amplos debates acadêmicos e, seguramente, já extrapolam as questões do sexo. Afinal, se a sexualidade passou a ser objeto de estudo é porque a sociedade contemporânea está preocupada com as relações de gênero e está desconstruindo os conceitos universais de ser homem e de ser mulher. Então, podemos ler nas entrelinhas a questão do gênero que está diretamente relacionada ao corpo.

Corpos de passagem, um conjunto de ensaios, não tem um caráter propriamente acadêmico. Os textos que compõem a obra não aprofundam as discussões teóricas das categorias envolvidas: corpo, subjetividade, indivíduo, por exemplo. Muitas áreas do conhecimento foram exploradas, e o elenco de autores/as franceses apresentados é significativo se comparado a poucos autores/as americanos (James Clifford, citado pelo seu trabalho etnográfico sobre comunidades sedentárias, e Donna Haraway, citada na sua abordagem sobre tecnociência e seres pós-gênero) e outros poucos/as pesquisadores/as brasileiros/as, como Heloisa de Farias Cruz, que aparece quando o assunto é a convivência entre pessoas e animais nas cidades (mostrando a utilização dos animais de carga na São Paulo das primeiras décadas do século passado); Beatriz Sarlo, quando se fala do modo de vida-zapping - dos dias atuais; e Celia M. T. Serrano e Heloisa T. Bruhns quando o assunto é turismo, cultura e ambiente. Entre os/as autores/ as em lígua francesa, aparecem: Monique Sicard, sendo referenciada quando o assunto é imagens; Peter Handke, Alain Ehrenberg e Jean-Luis Chrétier, na discussão sobre o charme da lentidão quando a contrapartida é a fatiga; Henri Béraud e Claude Fiscler, inspirando as fala sobre obesidade; Vladimir Jankélevitch, Jean-Pierre Peter, MarieChristine Pouchelle e Timothy Lenoir discutindo sobre morte, dor, hospitais e cirurgias; Bernand Edelman, sobre a publicidade da privacidade; Marc Guillaume e Pascal Bruckner, com seus respectivos trabalhos sobre a fábrica do riso e a euforia da felicidade; Dora Valayer, com o tema turismo; Michel Serres, com a idéia de pantopia; Andre Pichot e Vandana Shiva, quando a discussão gira em torno de ciência, genética e ética; Claude Olievenstein, que aborda o envelhecimento; e Francis Ponge, que apóia a autora quando trata da visão do homem no animal.

No campo da História, o tema do corpo, envolto pela subjetividade, é preocupação recente. As evidências com o corpo, bem como a sexualidade, tornaram-se debate freqüente na sociedade e fizeram emergir as problemáticas sobre o mesmo. Os historiadores estão se perguntando sobre o corpo porque a sociedade está colocando esse tema em evidência. Não se têm muitas respostas, ou talvez não tenhamos que tê-las. Todavia, a contribuição de Denise Sant'Anna, especialmente no campo da História, é muito importante. Até mesmo para percebermos o quanto os historiadores precisam discutir tanto com a Antropologia, a Psicologia e a Filosofia quanto com a Medicina, o Direito e outras áreas que cientificizaram o corpo e as relações humanas. Nesse momento, o trabalho de arqueólogo sugerido por Foucault ${ }^{2}$ é pertinente, não para trazer os 'monumentos' mudos, mas transformá-los em documentos tomados de sentidos pelo historiador.

O corpo foi dado a ler 'naturalizado' nas manifestações sobre doença, morte e velhice no 
século XIX e início do século passado, ou na busca de saúde e prazer infinitos contemporâneos. Esses contrapontos da 'natureza' dos corpos, como mostra a autora, são historicizados, mesmo que as temporalidades sejam efêmeras por não ter uma datação precisa ou presa no calendário de determinada cultura. Desconstruir as formas discursivas, como faz Denise Sant'Anna, é evitar o perigo de transformar o corpo em lugar dos universais.

1 Lucila Scavone traz essa discussão do primeiro momento do movimento feminista, baseado na noção de diferença e criando uma idéia de liberdade e autonomia das mulheres, associada a uma concepçao de conhecimento e reapropriação do próprio corpo. SCAVONE, Lucila. "Anticonceptión, aborto y tecnologías conceptivas: entre la salud, la ética y los derechos". In: SCAVONE, Lucila (Org.). Género y salud reproductiva en América Larina. Cartago: Libro Universitario Regional, 1999. p. 25-31.

${ }^{2}$ FOUCAULT, Michel. A arquelogia do saber. 3. ed. Rio de Janeiro: Forense-Universitária, 1987.

ANA MARIA MARQUES

Universidade do Vale do Itajaí

\section{A construção da 'natureza feminina' no discurso médico}

\author{
Uma ciência da diferença: sexo \\ e gênero na medicina da \\ mulher.
}

\section{ROHDEN, Fabíola.}

Rio de Janeiro: Editora FIOCRUZ, 2001, $223 \mathrm{p}$.

Produto de uma tese de doutorado em Antropologia Social, o livro de Fabíola Rohden analisa a temática da diferença sexual nos escritos médicos do século XIX e início do século XX, a partir das representações, das imagens que estão na base da criação da medicina da mulher. Inicialmente, diz a autora, a investigação visava a produzir uma história sobre a sexualidade e a reprodução. O exame da documentação, entretanto, revelou que, "em boa parte do século XIX especialmente, a medicina da sexualidade e reprodução era a medicina sobre a mulher, expressa sobretudo na criação de uma especialidade, a ginecologia, que se definia como 'a ciência da mulher'” (p.31).

Rohden persegue os caminhos tortuosos da construção de uma determinada concepção de diferença sexual entre homens e mulheres, demonstrando o empenho de médicos e cientistas europeus da época em estabelecer claras diferenças de caráter biológico e predeterminado entre os sexos. Essas diferenças não seriam apenas físicas, mas eram também psicológicas e morais. No discurso médico do século XIX, o sexo era entendido como um elemento natural e biológico, responsável pelo 'destino' social de homens como provedores e de mulheres como esposas e mães. Apesar dessa crença de que o sexo determinaria o destino, Rodhen chama a atenção para o que entende ser um paradoxo presente nos textos médicos: a diferença sexual era vista como natural e, ao mesmo tempo, como sendo 'instável' e 'perigosa'. Conseqüentemente, seria necessário monitorar o processo de diferenciação sexual de homens e mulheres, em particular no início da puberdade, fase na qual "as influências do meio poderiam prejudicar ou impedir que se chegasse ao resultado esperado, de amadurecimento sexual e reprodutivo de homens e mulheres" (p. 204).

Valendo-se da bibliografia existente sobre o assunto, transita por várias problematizações sobre a questão da diferença biológica e discussões teóricas elaboradas por autores/as como Thomas Laqueur, Londa Schiebinger, Michel Foucault, Ornella Moscucci, Cynthia E. Russet, Jill L. Matus, entre outros. No diálogo estabelecido com Laqueur, recupera a discussão sobre os dois modelos de interpretação do corpo feminino em relação ao masculino. O primeiro, herdado dos gregos, que admitia apenas uma estrutura básica do corpo humano, a do macho, teria prevalecido 